\title{
Understanding the decisional factors affecting consumers' buying behaviour towards organic food products in Kerala
}

\author{
Ms Krishna. $\mathrm{R}^{1}$ and Dr P. Balasubramanian ${ }^{2}$ \\ ${ }^{1,2}$ Department of Commerce and Management, Amrita University, India - 682024
}

\begin{abstract}
Rising concern for health and environmental issues associated with the rigorous use of chemical fertilizers has necessitated an alternate form of agriculture in Kerala, and that's how organic production came into existence. The organic agricultural production technique is considered to be quite conflicting with conventional production technique where the use of human-made fertilizers like pesticides, weedicides and insecticides are entirely banned. Organic products are perceived to be minimally processed to maintain the integrity of the food without artificial ingredients and preservatives. Therefore right from mid-eighties, consumers, particularly from the developed countries, started switching over towards organically produced food products as they more nutritious, healthy, and nature-friendly. Considering the organic market in Kerala, the state is still at its infant stage with a market share of less than $1 \%$. Hence it is critical to investigate Kerala consumers low consumption level towards environmentally friendly products. The current research intents to explore the factors influencing Kerala consumers' organic purchase behaviour based on data collected from 200 respondents (100 regular and 100 irregular organic users) using a structured questionnaire. Analysis techniques comprising of correlation and multiple linear regression has been applied for data evaluation. The research findings support the formulated hypothesis and aim at providing necessary guidelines for various stakeholders who are involved in the organic industry.
\end{abstract}

\section{Introduction}

The conventional method of agricultural production is considered to be one of the most significant threats posed to environmental sustainability as its function are dependent on the high level of energy and material cost involved in it. The emergence of green revolution has resulted in the extreme use of chemical fertilisers to upsurge the yields without any concern for environmental destruction. The biggest challenge in developing healthier communities begins with the concern for the environment because the consumer choice regarding the environment has influenced the quality of life for both future and current generations. Currently, the urge to create a healthy as well as a sustainable environment has initiated the interest in generating awareness among the consumers to be sensible about their consumption behaviour.

In the words of Vindigni [1], two fundamental criteria which determine consumers purchase intention towards organic products are his concern for health and environment. Conversely, his existing organic knowledge, government support policies towards organic marketing, consumers' perceived beliefs and attitudes should also be taken into consideration. Past studies reveal that there exist only a few numbers of pieces of literature emphasizing on how the change in price and availability of organic products in stores have an adverse effect over consumers' purchase intentions. Therefore it is crucial to investigate the factors which motivate as well as hinders consumers' organic food consumption, particularly among the developed countries.

\subsection{Organic food market in India}

Organic food products are predictably safe, produced using ecologically sound methods that do not involve synthetic inputs such as pesticides, chemical fertilizers or genetically modified organisms (GMOs) and without irradiation, industrial solvents, or chemical food additives. As per the published reports from APEDA [2], India is the ranked as the second-largest producer for organic products among the world market with the majority of them are small and marginal farmers. However, most of them are omitted from the export organic supply chains, and hence the only option left for small scale farmers is to sell their produce within the domestic market. Based on the research conducted by Dholakia [3], one of the main barriers for organic consumption is the high price. He also added that defining consumers' purchase decision process is difficult because awareness about the benefit gained organic consumption is far away from their food basket. The present situation indicates the importance to study consumers' buying behaviour towards organically produced products, 
particularly in Kerala.

\section{Theoretical background}

\subsection{Theory of Planned Behaviour (TPB)}

Theory of Planned Behavior suggested by Ajzen [4], stresses in the link between beliefs and behaviour, and it has been applied to studies of the relationships among beliefs, attitudes, behavioural intention and final purchase behaviour. The first variable behavioural beliefs refer to those attitudes towards the behaviour. It can also lead to a favourable or non-positive behavioural attitude. The second variable normative beliefs refer to the subjective norms or perceived social pressure to perform behaviour. Finally, Control beliefs refer to the perceived behavioural control or self- efficacy, which has been induced over a behaviour. Concerning the research conducted by Peter [5], the major problem concerning the Indian organic market is the existing gap between consumers' attitude and their behavioural pattern while purchasing organic products. This situation occurs when consumers have a positive attitude towards organic products, but they don't buy it. This inconsistency occurs when most consumers do not consider the question organically/environmentally produced as a determinant criterion for purchase and are not viewed as a substitute for conventional food as regards to taste and shelf-life, two attributes of great importance.

\subsection{Health Belief Model (HBM)}

The concept of Health Belief Model was developed by Irwin Rosen stock [6] in an attempt to predict and explain consumers' health behaviour focusing on their attitude and belief of individuals. Health Belief Model (HBM) is one of the most widely used conceptual frameworks for understanding health behaviour and is most often used in public health as a theoretical framework, Baghianimoghadam [7]. The present study has adopted this model in an attempt to find out consumers' willingness to adopt organic food products.

Pinto et al. [8] through his research found out health decisions are based on two major components, threat perception and behavioural evaluation which are divided into four psychosocial subcomponents or beliefs: perceived susceptibility, perceived severity, perceived benefits and perceived barriers. As per this model, a person is likely to change behaviour if he/she experiences (i) Perceived Susceptibility/Seriousness: which refers to the subjective assessment regarding the possibility of acquiring a risk which can be particular disease or a condition; (ii) Perceived benefits: indicating the positive benefits gained from participating in health-promoting behaviour or a belief that a change in behaviour will reduce risk.; (iii) Perceived Barriers: which refer to how one interprets the costs or barriers of the desired behaviour; (iv) Cues to Action: which denote stimuli that promote action or the strategies to activate readiness. (v) Self-Efficacy: which means feeling confident in one's ability or in their belief to engage in health-promoting behaviour.
According to the HBM, a consumer is more likely to use organic crops if he/she i) perceives him/herself to be susceptible to unhealthy food; ii) perceives the unhealthy food as a severe threat; iii) perceives the benefits of changing eating habits; iv) perceives that there is a limited barrier to changing eating habits; v) receives a cue to change and vi) is encouraged to change or prevented from changing due to self-efficacy, and vii) has a general health orientation that encourages or prevents him/her from changing. Janssen [9] identified, the Health Belief Model is best used when promoting individual preventive behaviours, such as a vendor or consumer purchasing or verification practices. Moreover, it focuses on the beliefs and perceptions of the individual, so it is appropriate to change behaviours that are not heavily influenced by society and social norms. The model mainly highlights how programs need to consider individual beliefs about the problem being addressed, and the costs and barriers associated with changing behaviour.

\subsection{Integrated Behavioural Model}

Integrated behavioural model (Figure 1) [10] is a combination of Theory of Planned Behaviour and Health Belief Model forms as the theoretical base for the current research. Theory of planned behaviour has been applied to find out what causes the change in consumer's organic product purchase through the direct measure of attitude, subjective norm and perceived behavioural control. Health Belief Model was applied to measure how far the consumers are conscious about their health, environment and various influencing factors affecting their purchase decision towards environment-friendly products.

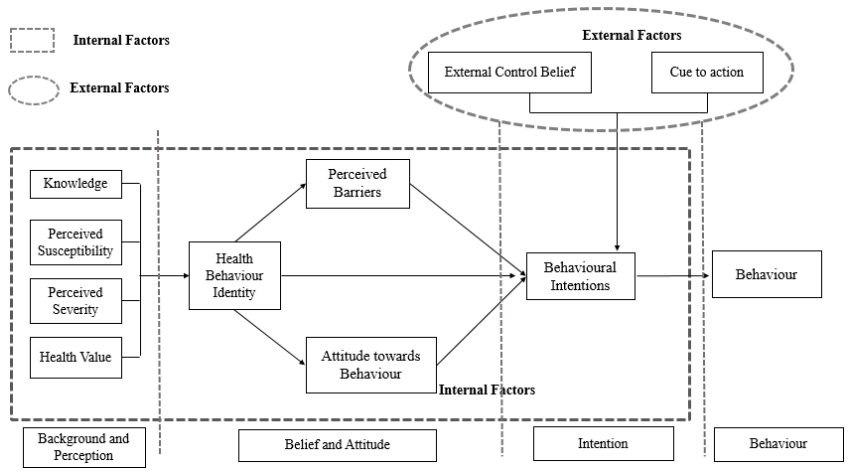

Fig. 1. Integrated Behavioural Model

\section{Variable identification}

\subsection{Knowledge}

Past works of literature highlight product knowledge, the nutritional value derived from it, quality, taste and environmental concerns are some of the critical factors affecting consumption pattern for organic products. In countries like India, the low awareness level is one of the main reason for the organic products to remain in its primary developing stage. Consumers need to be exposed 
to more information about organic food products to improve their knowledge of it. Therefore with higher knowledge, there is a greater probability to go for organic products, Radman [11].

H1: There is a positive relationship between knowledge and consumer behaviour towards organic foods.

\subsection{Attitude}

As reported by Thøgersen [12], Attitude has been regarded as a critical predictor towards the intention of consuming organic food such as fruits and vegetables. To be able to serve the needs of consumers, an understanding of the perception and attitudes of consumers is crucial. Based on the reviews from previous studies, the following sub-variables are likely to influence consumer attitude, and the corresponding hypothesis has been drawn from each concept.

\subsubsection{Health Consciousness}

Titterington and Cochrane [13] points out, those people with health consciousness are aware and concerned about their wellness in addition to being motivated to improve or maintain their health, and to prevent any ill health by involvement in health behaviours and being selfconscious about health.

\subsubsection{Environmental Concern}

Environmental concern is operationally defined as the extent to which people value or are worried about the environmental problems and possible measures which an individual is ready to undertake. The number of people who purchase organic food is for environmental reasons due to organic farming procedures are developed to help the environment, protect the quality and reduce pollution of water and earth. It is inferred that because consumers are becoming more concerned about the environment, they are willing to contribute to protecting it in any way possible, including buying organic food products. Consumer environmental consciousness makes them have a positive attitude towards buying organic food, Padel \& Foster [14].

\subsubsection{Willingness to Pay}

Price is considered as a crucial element in determining consumer's willingness to pay and hence the high or low price of a product may affect their decision making. Taking the case of Indian organic consumers, price act as a barrier for consumers to purchase organic fruits and vegetables due to its premium price. Regular users of organic products are prepared to pay an amount which is similar to those existing at present. Therefore, those consumers who are ready to have natural foods always look out for organic food and are willing to pay a higher amount, Gracia and Magistris [15].

\subsubsection{Consumers' Lifestyle}

Out of the research conducted by Thompson and Kidwell [16] in certain countries like Italy and the United States, people consider to purchase and consume organic products as an indicator of their status symbol. The purchase of such products turns out to be a sign of luxury and has become the latest trend within the elite class of society. It portrayed the purchasing power and luxurious lifestyle of consumers with higher disposable income.

\subsubsection{Consumers' Expectations}

There are limited studies that carefully examine consumer expectations towards the quality of organic products. Schleenbecker and Hamm [17] focused on consumer expectations for product characteristics of organic yoghurt, milk and apples, indicating that consumers do have expectations with regards to organic food. Identifying consumers' expectations concerning organic products is, therefore, of great importance.

Out of the variables identified the following hypothesis can be framed:

$\mathrm{H} 2$ : There is a positive relationship between attitude and consumer behaviour towards organic foods.

\subsection{Subjective Norms}

Kumar, Saravana and Jain [18] put forward the fact that those family circle or households with nuclear family seem to be more conscious of purchasing organic food products and exhibits a positive approach regarding the payment. The relevance of subjective norm as a construct has been widely disputed in theory. Still, it is usually found to be the weakest predictor of intention, and this feature has also been witnessed in domains exclusive of health. Besides, the presence of children in the family has a positive influence on purchasing organic food products due to the increased health consciousness and nutritional awareness. On that note, the following hypothesis has been proposed:

H3: There exists a positive relationship between subjective norms and consumer behaviour towards organic foods.

\subsection{Perceived Behavioural Control}

Perceived behavioural control can be defined as a person's perception of the ease or difficulty of performing the behaviour of interest. Perceived behavioural control has motivational implications on behaviour through intentions. It is referred to as the consumer's perception of personal control over what to buy and eat. Consumers are motivated to buy organic food because of the values, beliefs and norms about the environment, personal health, economy as well as religion. As mentioned by Squires and Cornwell [19], based on the study among the organic respondents, showed that perceived beliefs could influence the consumers to purchase organic foods the most.

H4: There is a positive relationship between perceived 
behavioural control and consumer behaviour towards organic foods.

\subsection{Socio-Demographic characteristics}

While purchasing an organic product, females and males have their tastes and preferences. Literature reviews found out that females are more likely to purchase green products because they are more concerned about the health and environment compared to males. Magnusson and Sjoden [20] discovered some recent studies showing age has an impact over the intention to purchase green products, indicating younger people make more straightforward in purchasing green decisions compared to older whose purchasing green decisions are more complicated because they are more cautious in choosing a product. Income level has a positive impact over environment sensitivity where consumers with high incomes and better occupation are more likely to buy green products compared to consumers with low income, Vehapi [21]. According to Gracia and Magistris [22], education is the most consistent results were found in the intention to purchase the green product. He added that consumers with higher education are more knowledgeable about green products and know the benefits of green products. On the word of Davies et al. [23], the presence of children within the household has also been regarded as a significant factor, which positively influences ones intention to purchase green. Those consumer having organic stores near to their residence seems to expose an increased purchase pattern.

H5: There exists a positive relationship between sociodemographic characteristics and consumer behaviour towards organic foods.

\subsection{Consumer Satisfaction, Trust and loyalty:}

\subsection{Consumer satisfaction}

Tao [24] suggested that when a consumer seems to be content with the firm's products or services, they will purchase it repeatedly and also recommend them to another potential consumer. No business enterprise can develop and flourish if they ignore or disregard the needs of their target consumers. On the other hand, a standard consumer tends to seek value in the total service provided right from the internal collaborations within the department, product documentation, till the final delivery of the product.

H6: There exists a positive relationship between consumer satisfaction and consumer behaviour towards organic foods.

\subsubsection{Consumer Loyalty}

Squires [25], outlines loyalty as a deeply held commitment to rebuild and re-patronize a preferred product or service in the future despite situational influences and marketing efforts having the potential to cause switching behaviours. He added that loyalty- building requires the company to focus the value of its product and services and to show that it is interested in fulfilling the desire or building the relationship with customers.

H7: There exists a positive relationship between consumer loyalty and consumer behaviour towards organic foods.

\subsubsection{Consumer Trust}

As mentioned by Anderson [26], consumer trust refers to the generalized expectancy held by an individual that the word of another can be relied on. Trust is an indispensable element in the organic food network as it has added value is mainly based on the production methods. Most consumers want their food to be explicitly certified and labelled as non-GMO, and due to the absence of chemicals and pesticides in organic food as well as its reputation for quality, most of the organic purchases were made to deal with food allergies and diseases. Therefore consumers believe organic products to be trustworthy.

$\mathrm{H} 8$ : There is a positive relationship between consumer trust and consumer behaviour towards organic foods.

\section{Empirical model applied}

Regarding research conducted by Fornell [27], the study of consumer buying behaviour towards organic food product is difficult because they are available in the market along with conventional ones and these products possess specific intense characteristics which may not be observable by the consumer but plays a vital role while shopping. Consumers purchase decisions depend on many factors which sharply varies across individuals which include their attitude towards these unnoticed organic foods characteristics such as environmental concern as well as self-care. Past research studies have set forth precise models which highlight the main factors influencing consumer behaviour towards the purchase of organic products.

Shivay [28] proposed a general model based on consumers' organic purchase behaviour focusing on notable factors such as product information, product perception and attitudes. He also found that consumers' attitude is one among the most influencing factor affecting consumers' purchase intention. Consumers' attitude is formed not only employing nutritional value, safety factors, environmental concerns, but by product perception. The next model was established by Shukla [29] in which consumers' green behaviour is determined by external factors which include consumers' sociodemographic characteristics and lifestyle while internal factors such as consumers' existing knowledge and environmental awareness. The relation between external as well as internal factors resulted in a new variable named as ecological implication encouraging organic consumer behaviour. As cited by Ajzen [4], a person's behaviour is determined by his/her intention to perform this behaviour. Intention can be defined as the cognitive representation of a person's readiness to perform a given behaviour, and it is considered to be the immediate 
antecedent of behaviour. The three significant factors which constitute one's intention are (i) Attitude: which denote the belief that a person accumulates over his lifetime. (ii) Subjective norm: which refers to what others will think about their behaviour and finally (iii) Perceived behavioural control indicating people's perceptions of their ability to perform a given behaviour. As per this theory, the more favourable the attitude, subjective norm and perceived control, the stronger the person's intention to perform the behaviour in question.

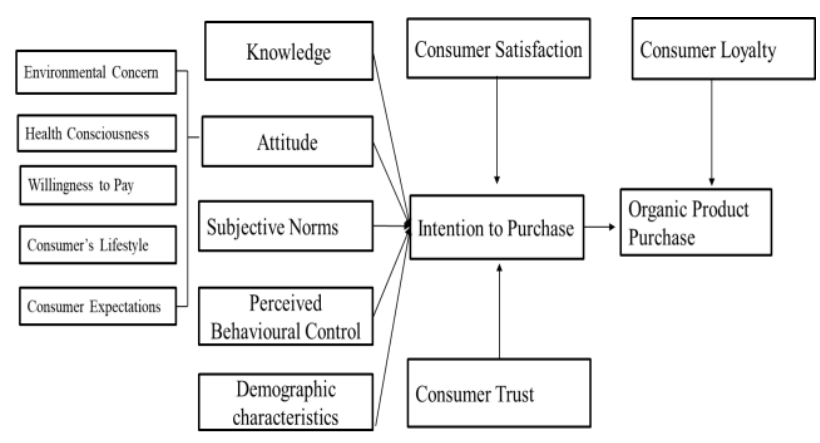

Fig. 2. Empirical Model Applied

Taking into account of all the three models, the following consumer organic buying behaviour model (Figure 2) [30] has been proposed. The above figure portrays the relationship between the independent as well as dependent variables for this study. The hypothesis so framed is intended to determine the factors influencing consumers' purchase decision. The figure explains that there around eight factors determining consumers buying behaviour which eventually leads to decide to purchase organic food. The variables represented in (Figure 2) [30] consist of both external as well as internal variables. The model suggests that consumers' organic food purchase behaviour depends on their intention to purchase, which in turn leads to final organic food purchase. The variables represented in square boxes are exogenous variables which influence endogenous variables. The inclusion of these variables is justified by the shreds of evidence obtained from previous empirical studies based on consumer intention and organic food purchase, as described in the next section.

\section{Materials and methods}

The study has been carried through a sequential description of research methods to figure out factors influencing consumers' organic purchase. The study sample consisted of 200 respondents (100 regular and 100 irregular users of organic products) selected through a multistage stratified random sampling method. The locations for selecting the respondents were based on stores including wholesale as well as retail organic stores and supermarkets that have dedicated organic food sections. The response time taken for each questionnaire was about 20-25 min. Answers were given using a 5 point Likert scale where responses ranged from 1= "Strongly Agree" to $5=$ "Strongly Disagree". Respondents approached were communicated that this questionnaire is only for those who have bought an organic product at least in the last eleven or twelve months. The sample size was determined using Morgan's Sample Size determination formula. The collected data were analyzed using a quantitative approach which includes Correlation Analysis and Multiple Regression Analysis.

\section{Findings from empirical data}

As per table 1, the mean for all the variables is in the range of 3.6201 to 4.1861. The results obtained from the mean indicates that respondents were generally agreed or has no specific clarifications regarding the questionnaire. The results reveal that the standard deviation for consumer purchase intention can be accepted as it is concentrated to its mean. The rest of the variables are less concentrated as the standard deviations differ from the mean value.

Table 1. Descriptive Analysis of all variables

\begin{tabular}{|l|c|c|}
\hline Variables & Mean & $\begin{array}{c}\text { Standard } \\
\text { Deviation }\end{array}$ \\
\hline $\begin{array}{l}\text { Consumer Purchase } \\
\text { Intentions }\end{array}$ & 4.1861 & .40841 \\
\hline Knowledge of the Consumer & 4.0540 & .41271 \\
\hline Attitude & 3.6247 & .43267 \\
\hline Subjective Norms & 4.1725 & .47602 \\
\hline $\begin{array}{l}\text { Perceived Behavioural } \\
\text { Control }\end{array}$ & 3.9374 & .57737 \\
\hline Demographic Characteristics & 3.6642 & .51001 \\
\hline Consumer Satisfaction & 3.6201 & .57106 \\
\hline Consumer Trust & 3.5341 & .46311 \\
\hline Consumer Loyalty & 3.6231 & .57253 \\
\hline
\end{tabular}

\subsection{Reliability Analysis:}

Reliability test was applied to examine how far research instruments used are stable and consistent to measure the construct. The results reveal that the coefficients of Cronbach's alpha for all variables were ranged from 0.723 to 0.846 , representing the consistency between each factor is excellent. Moreover, all the independent variables preferred was reliable because the reliability coefficients indicate 0.83 for knowledge (0.831), attitude (0.817), subjective norms (0.841), and perceived behavioural control (0.826). The exceptions were demographic characteristics (0.788), consumer satisfaction (0.752), consumer trust $(0.750)$ and loyalty which obtained $(0.723)$ as its reliability coefficient.

\subsection{Correlation Pearson Analysis:}

In this study, Karl Pearson's coefficient of correlation is implemented to measure the strength of a linear relationship between two variables. The results from Correlation Analysis (Table 2) reveals that (i) the correlation between knowledge and consumer behaviour depicts R-value of 0.512 or $51.2 \%$ at $99 \%$ confidence interval showing a strong relationship between the two variables; (ii) the correlation between attitude and consumer behaviour indicates R-value of 0.343 or $34.3 \%$ 
at $99 \%$ confidence interval depicting a moderate relationship between these two variables; (iii) there exist a moderate relationship between subjective norms and consumer behaviour as the $\mathrm{R}$-value is 0.356 or $35.6 \%$ at 99\% confidence interval; (iv) the next correlation is between perceived behavioural control and consumer behaviour, R-value being 0.590 or $59 \%$ at $99 \%$ confidence interval indicating strong relationship; (v) The correlation continues to correlate between demographic characteristics and consumer behaviour, $\mathrm{R}$-value is 0.568 or $56.8 \%$ at $99 \%$ confidence interval proposing a strong relationship between the two variables. (vi) the next variable is consumer satisfaction correlating with consumer behaviour, R-value 0.567 or $56.7 \%$ at $99 \%$ confidence interval indicating a moderate relationship. (vii) there exist a correlation between consumer trust and consumer behaviour, indicating a moderate relationship with r- value 0.473 or $47.3 \%$ at $99 \%$ confidence level. (viii) The last variable being consumer loyalty correlates with consumer behaviour resulting in $r$ value of .466 or $46.6 \%$ at $99 \%$ confidence interval depicting a moderate relationship between two variables.

As stated in Hypothesis 1, a higher knowledge level will lead to increased purchase behaviour of consumers towards organic food is supportive as knowledge being found to have a significant effect (sig. $t=0.007$ ) on consumer buying behaviour. The findings incurred seems to be consistent with the finding of [31], in which insufficient knowledge about organic foods will directly affect organic food purchase and consumption. To conclude, Consumers' organic knowledge depends on the extent of knowledge possessed by them. Hypothesis 2 proposes that there exist a significant positive relationship between their attitudes, organic purchase behaviour. It can be shown with its (sig.t $=0.005$ ), and the hypothesis is supported. These findings are in line with the statement that consumers who possess a positive attitude towards the purchase of organic products seem to have increase purchase pattern. The result obtained is very similar to the research done by [32]. Hypothesis 3 shows that there is a significant relationship between subjective norms and consumers intention to purchase organic products which are supportive with its (sig.t $=0.009$ ). This is in line with research findings from [33] stating that the presence of children in the family has a positive influence over purchasing organic food products due to the increased health consciousness and nutritional awareness. As per Hypothesis 4, perceived behavioural control has a positive relation towards organic foods consumption is supportive with (sig.t $=0.006$ ). This finding is consistent with the research done [34], which claims that a consumer always beliefs in his ability to solve environmental problems that have been linked directly to the purchase of green products and it becomes one of the vital predictors of environmentally conscious behaviour.

Hypothesis 5 recommends that consumers' sociodemographic characteristics will influence their intention to purchase organic food. The hypothesis so framed is supportive with (sig.t $=0.009$ ). This statement is supported concerning the research conducted by [35] in which age has an impact over the intention to purchase green products, indicating younger people make more straightforward in purchasing green decisions compared to older people whose purchasing green decisions are more complicated because they are more cautious in choosing a product. As stated in Hypothesis 6, there exists a significant positive relationship between consumer satisfaction and consumer behaviour towards organic foods with (sig.t $=0.002)$. This statement is supported regarding the research conducted by [36] wherein they claimed that consumer satisfaction is a barometer that predicts future consumer behaviour. The overall quality of the product, its appearances, utilities, dependability, promotions and consumer care are the most fundamental mandatory requirements needed to attain the satisfaction of the consumers. Following Hypothesis 7, there exists a positive relationship between consumer loyalty and purchase intention towards organic products with (sig.t $=$ 0.004). The hypothesis framed is supportive as it agrees with the research conducted by [36], in which consumer loyalty to be more cost-effective. This is because the expenses incurred on attracting a new consumer is much more than retaining the existing one.

Conversely, the loyal consumers will inspire others to purchase the firm's product and thereby increasing the overall profit. Lastly, Hypothesis 8, reveals that there exists a significant relationship between consumer trust and consumer buying behaviour towards organic foods, and this hypothesis is also supported with its ( $\mathrm{sig}$. $\mathrm{t}=$ 0.032). Previous studies also found that consumers tend to trust organic products when its consumption enables them to lead a healthy lifestyle [37].

Table 2. Result of Correlation Analysis

\begin{tabular}{|l|l|l|l|l|l|l|l|l|l|}
\hline & BV & KW & AT & SN & PBC & DC & CS & CT & CL \\
\hline $\begin{array}{l}\text { Pearson } \\
\text { Correlation }\end{array}$ & & & & & & & & & \\
\hline Behaviour (BV) & & & & & & & & & \\
\hline KW & $.512^{* *}$ & 1 & & & & & & & \\
\hline AT & $.343^{* *}$ & $.470^{* *}$ & 1 & & & & & & \\
\hline SN & $.356^{* *}$ & $.310^{* *}$ & $.624^{* *}$ & 1 & & & & & \\
\hline PBC & $.590^{* *}$ & $.483^{* *}$ & $.475^{* *}$ & $.394^{* *}$ & 1 & & & & \\
\hline DC & $.568^{* *}$ & $.403^{* *}$ & $.493^{* *}$ & $.500^{* *}$ & $.534^{* *}$ & 1 & & & \\
\hline CS & $.567^{* *}$ & $.211^{* *}$ & .083 & .151 & .107 & $.262^{* *}$ & 1 & & \\
\hline CT & $.473^{* *}$ & $.275^{* *}$ & .145 & $.235^{*}$ & $.372^{* *}$ & $.274^{* *}$ & $.319^{* *}$ & 1 & \\
\hline CL & .466 & $.266^{* *}$ & .128 & $.222^{*}$ & $.367^{* *}$ & $.268^{* *}$ & $.310^{* *}$ & $.312^{* *}$ & 1 \\
\hline
\end{tabular}




\section{Discussion and conclusion}

The research aims to determine the factors influencing consumers' buying behaviour towards organic food products in Kerala. Based on the survey conducted respondents organic knowledge, their attitude, environmental concern and extend of satisfaction, trust and loyalty possessed by them seem to have the most influence over their purchase intentions. Analysis based on consumers' socio-demographic profile indicates that respondents belonging to both young and aged group are more likely to purchase organic products. Amongst those female consumers seems to be more dominant in the market. Over the years, there seems to an increase in interest towards organically grown as consuming it enables them to enhance their health.

It was also noticed that respondents are anxious about the adverse effects of using pesticides and other chemical compounds in the farms. Moreover, the increased consciousness for environmental concerns has raised the demand for environment-friendly products. Gradually a transformation occurred in consumer's attitudes and purchased intentions when they found out the prerequisite of preserving resources for future generations, problems associated with saving the environment and supporting local small scale farmers. In contrast, lack of trust regarding the organic certification and non-availability of products in stores are the notable factors which refrained them from repeated purchase. Additionally, it was also observed that consumers prefer to purchase from specialised organic retail stores as there is an insufficient supply of organic products in hypermarkets.

Based on the findings put forward, the current research will be useful for the marketers to be vigilant in understanding the needs as well as to find out the major demand drivers for organic food products. It enables them to explore the unknown factors which refrain consumers' organic purchase. The study suggests that marketers need to bring out innovative strategies for retaining the consumers and in turn, convert them into loyal customers. The perceptions of this research can be useful to the marketing managers to decide on their market segments and thereby target potential consumers. It enlightens specific questions of how organic food can be made available in different retail store formats, how it can be less expensive and make them an indispensable part of consumers' life.

Secondly, the study proposes a suggestion to the government. Research findings indicate that government support and policies for organic products tend to create a positive influence over consumers purchase decisions. Therefore the government has to actively participate in providing information regarding organic farming practices, subsidies, guidelines and workshops to the local farmers as well as to the consumers. As a measure to spread consumption towards the public at large and bring a change in general shopping trend, the organic industry in Kerala has to come up with a strong network of information along with improved infrastructure. It is recommended that through constant support from the government or ruling parties to restructure the existing mechanisms and also by assisting the farmers can enhance the production as well as awareness on organic products among the local buyers which in turn helps in the faster progression of organic farming.

Consumer behaviour act as a decisive determinant not only while purchasing organic products but also any products. The study has highlighted the prime areas like distribution, marketing, ethical consumerism must be modified for future research that may be directly or indirectly helpful in expanding the market and increasing the reach for organic food products globally. This intends to highlight that consumers in developing countries are acute to purchase organic food, which is quite popular in developed countries as well. Lack of effective distribution and promotion systems among organic products has created a significant influence on the familiarity as well as on accessibility. They desire to have organic shops nearby with product varieties in stock which offer reasonable price. Timely availability of organic products in stores affecting consumers' intention to purchase is providing information for the marketers to modify their marketing strategies and distribution channels as well. Promotional strategies adopted by the marketers tend to create a sense of positive attitude, perception and belief within the consumers.

As things stand, the organic market in Kerala is inexperienced and underdeveloped. The marketers of organic products have to be more innovative and dynamic to meet the shifting purchase pattern for organic food products among urban residents. Therefore those firms who are involved in the production along with distribution of organic products have to find ways to create trust among the consumers to improve their purchase intention. In short, steps to increase organic consumption has to be adopted within organic and inorganic consumers within Kerala district.

\section{References}

1. Vindigni, Organic food consumption: A multitheoretical framework of consumer decision- making . British Food Journal, Vol.104 (8): p.624-64, (2016).

2. Agriculture and Processed Food Product Development Authority: Report on Organic Food Export to EU, p. 23-27 (2018).

3. Dholakia, Indigenous marketing practices and theories in emerging economies: Consumer behaviour and retail transformations in India. Journal of Business Research, Vol. 86, p.406-415 (2018).

4. Ajzen, Influencing Attitudes and Behavior. Contemporary Psychology: A Journal of Reviews, Vol. 26(12), p.964-966 (1991).

5. Peter and Olson, Consumer Behavior and Marketing Strategy, 8th International Edition, McGraw- Hill Companies Inc., New York, p.46 (2018). 
6. Irwin and Rosen stock, Faculty History Project, Vol. 5(12) p.160 (1950).

7. Baghianimoghadam, Related factors to choose normal vaginal delivery by mothers based on Health Belief Model. Journal of Education and Health Promotion, p.17 (2019).

8. Pinto, Using the health belief model to test factors affecting patient retention in diabetes-related pharmaceutical care services. Research in Social and Administrative Pharmacy, Vol. 2(1), p.38-58 (2006).

9. M. Janssen, Organic food consumption: A multitheoretical framework of consumer decision making. British Food Journal, Vol. 104(8), p. 624-642 (2018).

10. Figure 1, Integrated Behavioural Model, developed from the combination of TPB and HBM, p.3.

11. M. Radman. Consumer consumption and perception of organic products in Croatia. British Food Journal, Vol. 107 No. 4-5, p. 263-273 (2016).

12. J. Thøgersen, Psychological Determinants of Paying Attention to Eco-Labels in Purchase Decisions: Model Development and Multinational Validation. Journal of Consumer Policy, Vol. 23(3), p.285-313 (2017).

13. Titterington and A. Cochrane, "Who buys organic food? A profile of the purchasers of organic food in N. Ireland", British Food Journal, Vol. 97 No. 10, p. 17-23 (2018).

14. Padel \& Foster, Exploring the gap between attitudes and behaviour - understanding why consumers buy or do not buy organic food, British Food Journal, Vol. 107 No. 8, p. 606-25 (2012).

15. A. Gracia and Magistris, The demand for organic foods in the South of Italy: A discrete choice model", Food Policy, Vol. 33, p. 386-396 (2018).

16. Thompson and Kidwell, Explaining the Choice of Organic Produce: Cosmetic Defects, Prices, and Consumer Preferences, American Journal of Agricultural Economics, Vol. 80(2), p.277 (2011).

17. Schleenbecker, R. and Hamm, U. Consumers' perception of organic product characteristics. A review. Appetite, 71, p.420- 429 (2015).

18. V. Kumar, Saravana and K. Jain. Marketing of Organic and Minor forest produce, Indian Journal of Agricultural Marketing, p. 21 (2013).

19. Squires and Cornwell, Level of market development and intensity of organic food consumption: a crosscultural study of Danish and New Zealand consumers, Journal of Consumer Marketing, Vol. 18(5), p.392-409 (2010).

20. Magnusson and P. Sjoden, Attitudes towards organic foods among Swedish consumers", British Food Journal, Vol. 103(3), p.209-226, (2018).

21. Vehapi, A study of the consumer motives which influence the purchase of organic food in Serbia, Economic Themes, Vol. 53, No. 1, p. 102-118 (2017).

22. A. Gracia and Magistris, T, The demand for organic foods in the South of Italy: A discrete choice model,
Food Policy, Vol.33, p. 386-396 (2018).

23. A. Davies, Titterington and C. Cochrane "Who buys organic food? A profile of the purchase of organic food in Northern Ireland", British Food Journal, Vol.97 (10), p.17-23 (2014).

24. F. Tao, Customer Relationship management based on Increasing Customer Satisfaction. International Journal of Business and Social Science, Volume. 5, Issue. 5, p. 256-263 (2014).

25. L. Squires and T. Cornwell, Level of market development and intensity of organic food consumption: a cross-cultural study of Danish and New Zealand consumers, Journal of Consumer Marketing, Vol.18(5), p.392-409 (2010).

26. J. Anderson and W. Gerbing. Structural equation modelling in practice: a review and recommended two-step approach. Psychological Bulletin, Vol. 103 (3): p. 411-423 (2016).

27. C. Fornell and D. F. Larcker Evaluating structural equation models with unobservable variables and measurement error. Journal of Marketing Research Vol. 18(2): p. 39-50 (2017).

28. Shivay, Organic Farming in the Context of Food Quality, Climate Change and Sustainable Agriculture. Employment News (Weekly), p.29-33 (2019).

29. Shukla, Organic Farming: Current Status in India. Popular Kheti - Special Issue on Organic Farming, Vol. 1(4), p.19-25 (2013).

30. Figure 2, Empirical Model Applied, developed from the current research-based on past literatures reviewed, p.6.

31. H. Hill and F. Lynchehaun, Organic milk: attitudes and consumption patterns. British Food Journal, Vol. 104(7), p.526-542 (2016).

32. Magistris and Gracia, The demand for organic foods in the South of Italy: A discrete choice model", Food Policy, Vol. 33, p.386-396 (2018).

33. Solar \& Sanchez, Consumers' Acceptability of Organic Food in Spain: Results from an Experimental Auction Market, Brit. Food Journal, Vol. 104, p.670687 (2012).

34. Rokeach, Consumer behaviour and purchase intention for organic food, Journal of Consumer Marketing, Vol. 29 Issue: 6, p. 419.

35. Thompson and Kidwell, Explaining the Choice of Organic Produce: Cosmetic Defects, Prices, and Consumer Preferences. American Journal of Agricultural Economics, Vol. 80(2), p.277 (2011).

36. M. Magnusson, Attitudes towards organic foods among Swedish consumers", British Food Journal, Vol. 103(3), p.209-226 (2018).

37. Gul and F. Soler, Knowledge and willingness to pay for organic food in Spain: Evidence from experimental auctions. Food Economics 3: p.109124 (2014). 